\title{
Los sonidos del vuelo trascendente ${ }^{1}$
}

\author{
Mónica Gudemos \\ Arqueomusicología, Área de Estudios Antropológicos de la Música \\ Centro de Producción e Investigación en Artes (FFyH) \\ Universidad Nacional de Córdoba (Argentina) \\ mgudemos@gmail.com
}

Recibido: 7 de septiembre de 2011

Aceptado: 5 de octubre de 2011

\begin{abstract}
RESUMEN
Los módulos de afinación prehispánicos de tradición huari, en estrecha relación con el sistema de medición Pichqa-tawa, fueron sin duda producto de una mano de obra especializada aplicada a la construcción de objetos con función sonora que, seguramente, respondió a una demanda en igual orden de especialización, posiblemente ceremonial. En el Horizonte Medio, coincidiendo con la expansión Huari, se observa la aparición de un tema iconográfico con probable impronta cultural sud-costeña, fuertemente asociado con las actividades ceremoniales y los llamados «vuelos extáticos», que tiene por motivo central un personaje, aparentemente de elevado rango, en posición ventral con la cabeza torsionada hacia arriba/atrás, al igual que sus miembros inferiores. Generalmente, en las iconografías Recuay, Chincha y Huari este personaje tañe una flauta característica, como las flautas óseas Huari que analizamos en nuestra investigación.
\end{abstract}

Palabras clave: Arqueomusicología andina, flautas Huari, iconografía prehispánica.

\section{The Sounds of the Transcendental Flight}

\begin{abstract}
The reconstructed pre-Hispanic tuning modules of the Huari tradition in correspondence with the specific unit of measurement Pichqa-tawa (Gudemos 2009b, 2011a) were without doubt product of a skilled labour applied to the construction of objects with sonorous function. Securely this skilled labour also responded to a skilled demand, possibly ceremonial. In fact, in the Middle Horizon, with the Huari expansion, a recurrent iconographical theme of probable south-coastal Peru tradition appears. This theme is strongly associated with ceremonial activities and the ecstatic shamanic flights (Berenguer 1987, Reichel Dolmatoff 1988, Olsen 2005, between other). Its central motif is a personage, apparently of high rank, in ventral position with his legs and head uphold. Generally, in the Recuay, Chincha and Huari iconographies this personage blows a short tubular notch flute with three or four front orifices, just like the Huari flutes analyzed in our research. This article deals with the relationship between these ceremonial practices, the existence of a skilled musical demand-production and the analyzed Huari bone flutes.
\end{abstract}

Key words: Andean archaeomusicology, Huari flutes, pre-Hispanic iconography.

Sumario: 1. Introducción: flautas óseas de tradición Huari. El emergente material de un sistema de definición acústica. 2. El poder de las mujeres que vuelan y una demanda ritual especializada. 3. Los sonidos del vuelo del yajé. 4. El vuelo extático. 5. Alucinógenos, «vuelo extático» y simbología iconográfica. 6. Consideraciones finales. 7. Referencias bibliográficas.

1 Parte de este trabajo fue presentado como ponencia en el XII Congress of the ICTM Study Group for Music Archaeology: Sound \& Ritual in Music Archaeology Bridging Material \& Living Cultures. Valladolid Septiembre de 2011. 


\section{Introducción: flautas óseas de tradición Huari. El emergente material de un sistema de definición acústica}

Todo comenzó en el año 2000, en los laboratorios del Museo de América de Madrid [MA], cuando las bases de datos de un particular grupo de flautas óseas arqueológicas de tradición Huari ${ }^{2}$ arrojaron los primeros índices. Éstos constataban por metodología estadística nuestras observaciones musicológicas efectuadas con anterioridad (Gudemos 1998) sobre un total de $54^{3}$ ejemplares taxon $421.111 .12^{4}$ procedentes de la Costa Central de Perú. Tales observaciones nos permitieron enunciar la hipótesis de la existencia de sistemas de definición acústica en el Mundo Andino Prehispánico, esto es de sistemas que establecían órdenes específicos de afinación. A través de los índices pudimos determinar con bastante exactitud diferentes módulos de afinación, todos ellos relacionados con un mismo sistema de definición acústica por relación de longitudes proporcionales (Gudemos 2001a, 2001b; 2006, 2009a). Estos módulos evidenciaban la existencia de complejas organizaciones sonoras prehispánicas, en las que el llamado «pentafonismo andino» era sólo un componente ${ }^{5}$. Tal vez, lo más significativo para nosotros en estos estudios técnicos y contextuales, fue considerar la posibilidad de que dichas organizaciones sonoras respondieron a concepciones de tiempo y espacio diferentes a las nuestras y que, por lo tanto, exigían el diseño de metodologías más apropiadas para su estudio.

De inmediato surgió en nuestra investigación un interrogante de carácter operativo: ¿Qué sistema de medición subyacía en la demarcación de cada módulo de afinación y cómo respondía a la adaptación proporcional de dichos módulos a las diferentes longitudes acústicas de los tubos óseos? Ante nuevas evidencias, enunciamos como hipótesis que el principio de correlación de longitudes proporcionales, a partir del cual se determinaba la demarcación de los diferentes módulos de afinación individualizados, era un sistema primario de medición, articulado a su vez por una típica complementariedad andina de orden $5-4$, «pichqa-tawa», respectivamente. Este principio se aplicaría en los tubos acústicos (esto es, cañas óseas preparadas como tubos de flauta) para la demarcación de los diferentes orificios de obturación por una sencilla relación simétrica de división binaria.

2 Pertenecientes a las colecciones del Ethnologisches Museum de Berlin [EM], del Museo Inka de la Universidad San Antonio Abad de Cusco [MIC] y del Museo Arqueológico y Antropológico de la Universidad Nacional Mayor de San Marcos de Lima [MUSM].

3 A los 54 ejemplares considerados en primera instancia, se sumaron aquellos estudiados en el Museum für Völkerkunde München [MVM] en 2003 y los ejemplares del [EM] analizados en 2000, que no tratamos en los primeros análisis estadísticos. De los ejemplares seleccionados (82 en total) se exceptuaron 3, correspondientes al posible sexto módulo de afinación, Chancay $[\mathrm{Gb}]$. Los índices correspondientes a la disposición de los orificios de obturación de cada uno de los 79 ejemplares restantes, responde al rango de alguna de las tipologías determinadas en esta investigación, hecho que sin duda deja en evidencia la existencia de una notable tradición musical en el Mundo Andino prehispánico. Recientemente, consideramos también los ejemplares de flautas óseas Huari del Museo de La Plata, cuyos índices se corresponden con la tipología Pachacámac.

4 Aerófonos de soplo (flautas), longitudinales, aislados, abiertos sin canal de insuflación con agujeros.

5 En nuestra investigación experimentamos en laboratorio con la emisión sonora de reproducciones de aerófonos andinos prehispánicos. Esto nos ha permitido constatar la existencia de un interesante rango de posibilidades acústicas que, desde el punto de vista de la afinación, contemplaría una interesante diastematía microtonal. Al respecto véase Olsen 2005, Gudemos 2009a, Gudemos y Catalano 2009. 


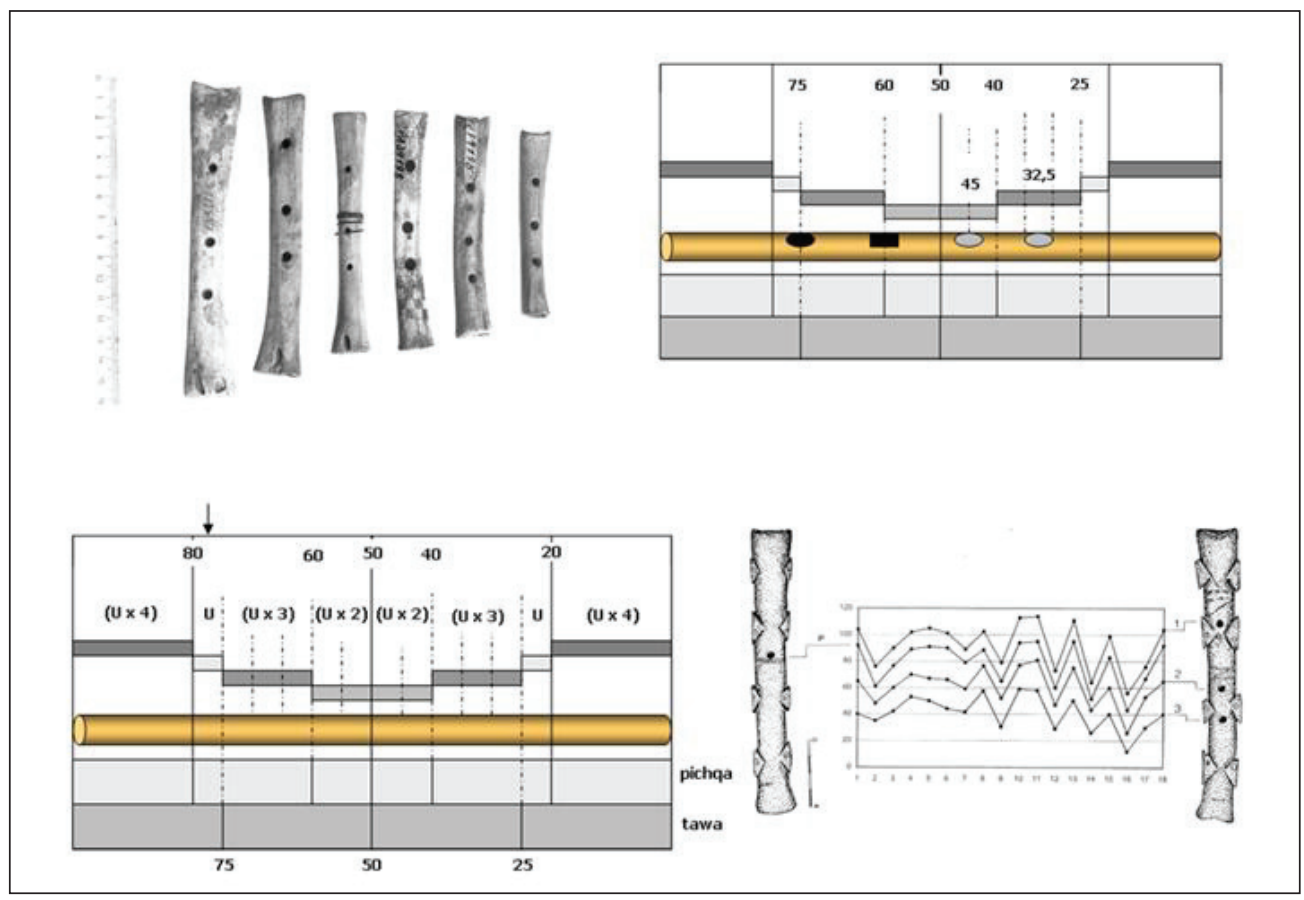

Figura 1: Tipología Pachacámac. Arriba: Cara anterior de los ejemplares VA39166, VA37636, VA39182, VA39198, VA39158, VA38164 del [EM]. Fotografías gentileza [EM] (Gudemos 2001b). Gráfico de determinación del Módulo Pachacámac a través del sistema pichqa-tawa. Abajo: Gráfico del sistema de medición pichqa-tawa. Con flecha se indica la unidad (U) del sistema. Gráfico estadístico de la distribución de los orificios de digitación en la tipología Pachacámac. Ejemplar dibujado como modelo: VA39202 [EM]. Ordenadas = distancia de cada orificio al borde inferior de la flauta (en $\mathrm{mm})$. Abscisas $=$ cantidad de ejemplares considerados en uno de los estudios estadísticos.

Cuando en el 2009 expusimos a evaluación la demostración de esta hipótesis (Gudemos 2009b ${ }^{6}$, se analizó la posibilidad de que este sistema hubiese sido empleado por los andinos para diferentes mediciones y no sólo en la determinación acústica, donde se observaba una notable precisión (Gudemos 2011a). Así, conceptualmente, estamos frente a un sistema de determinación acústica que acusa un interesante manejo de sonidos correlativos, esto es de estructuras acústicas cuyas relaciones entre sonidos habrían interesado más a los complejos culturales productores ${ }^{7}$ que las frecuencias puntuales e independientes. No hablamos aquí de rangos de tesitura ni de alturas específicas, sino del sonido comprendido en una organicidad de estructuras

6 En el marco del XVI Congreso Peruano del Hombre y la Cultura Andina y Amazónica. Universidad Nacional Mayor de San Marcos. Lima, Octubre de 2009.

7 Específicamente, nos referimos a los complejos culturales asentados en la Costa Central de Perú en los periodos de Expansión Huari (600-1000 d.C., aproximadamente) y de los Estados Regionales (1000-1400 d.C.). No obstante, esta determinación cultural de organizaciones sonoras tendría una larga tradición (que creemos procedente de la Costa Sur Peruana) y habría alcanzado una amplia difusión espacio-temporal. En nuestros estudios hemos registrado ejemplares incaicos de flautas óseas de igual taxonomía, que acusaron la aplicación de los módulos de afinación aquí tratados. 
modales que, como observamos en otros trabajos (Gudemos 2011a), ya no podremos determinar por la ausencia de referentes sociales originales, es decir, de expresiones musicales en las que se utilizaban estas flautas. Por cierto, lo antes dicho no nos impide conjeturar acerca de la posibilidad de que tales estructuras hayan estado vinculadas a la «representación» o «identificación» musical de determinados estamentos o involucradas en actividades rituales de elite en el ceremonial comunitario. Si así fue, podríamos hablar incluso de la búsqueda de un «sonido social» o un «sonido ceremonial», concepciones no extrañas entre los andinos (Gudemos 2005, 2008).

A

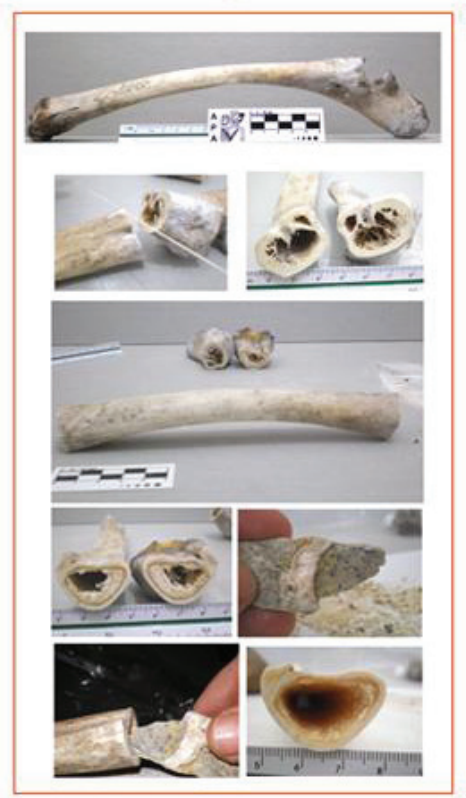

B
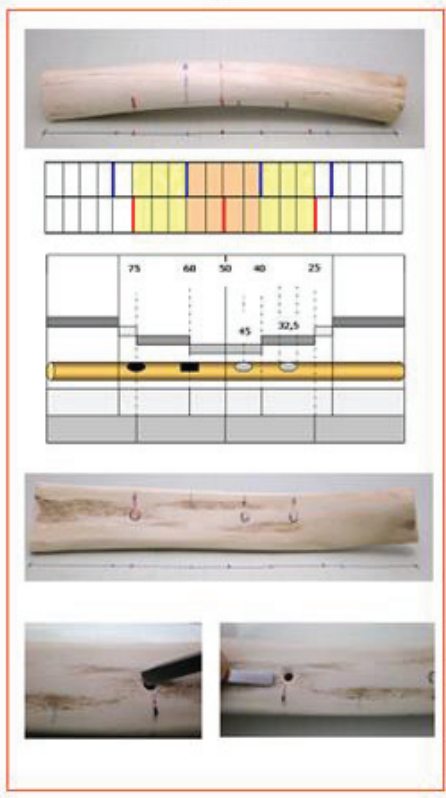

C

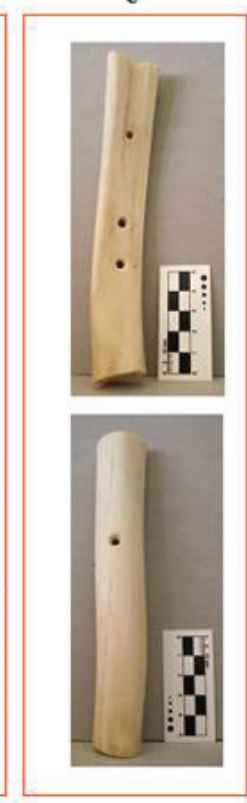

Figura 2: A: Proceso de construcción de una flauta Pachacámac a partir de un radio/ulna de llama (Lama glama). B: Aplicación del sistema pichqa-tawa para la determinación de su afinación y perforación de los orificios de digitación. C: Flauta terminada (abajo, cara posterior; arriba, cara anterior).

En nuestra investigación experimentamos directamente con materiales naturales, utilizando técnicas primarias preindustriales de construcción. En la Figura 2 mostramos diferentes etapas de fabricación de una flauta tipo Pachacámac (véase detalles de su análisis en la Figura 1). Esto facilita una aproximación técnica al manejo acústico de los materiales, así como una constatación de hecho en la aplicación de los módulos de afinación y sistema de medición. Al mismo tiempo nos obliga a reflexionar sobre una economía regional que contemple tanto la disponibilidad de los recursos naturales empleados, como el sustento y desarrollo de una mano de obra especializada, puesto que, en este caso, no estamos ante un producto de aficionados. 


\section{El poder de las mujeres que vuelan ${ }^{8}$ y una demanda ritual especializada}

Lamentablemente, los datos sobre los contextos de hallazgo de estas flautas son escasos, pero de algo estamos seguros, la precisión en la determinación acústica que observamos sólo podía estar a cargo de una mano de obra especializada, respondiendo sin duda a una demanda en igual grado de especialización. Asimismo, por la dispersión geográfica y temporal de estas flautas de tradición Huari, con mayor concentración en la Costa Central de Perú en áreas regionales como Pachacámac, Ancón y Chancay ${ }^{9}$, pensamos en la existencia de una base cultural que consideró importante la conservación y desarrollo de un sistema de determinación acústica tan preciso. Por otra parte, sabíamos de la existencia, en el Mundo Andino prehispánico, de músicos profesionales y prácticas musicales «institucionalizadas» a través del estudio de fuentes primarias, iconografías y contextos funerarios (Gudemos 2005, 2008 y 2009c). Sin embargo, aún nos faltaban referentes probatorios que nos permitiesen conjeturar sobre la función social de estas pequeñas flautas óseas en particular.

Tras los recientes hallazgos y estudios publicados por el Programa Arqueológico San José de Moro en el Valle de Jequetepeque, Perú, comenzamos a tener datos que respaldaban nuestros presupuestos sobre la función ritual de estas flautas ${ }^{10}$. Las claras evidencias de una importante influencia estilística huari en el Valle de Jequetepeque, a partir de los últimos momentos del Periodo Mochica Tardío y, principalmente, del Periodo Transicional (Castillo Butters y Rengifo Chunga 2008: 5) ${ }^{11}$, son fundamentales para la contextualización cultural de estos aerófonos. Al respecto, Ilana Johnson (2008: 267) observa:

«The site most relevant to the study of Portachuelo de Charcape is San José de Moro, which is located only a few kilometers away on the valley floor near the Chamán River. There is evidence of a Middle Moche occupation at San José de Moro, but it is a «distinct cultural phenomenon» from the Late Moche Period remains found at the site. The Late Moche Period in the north is characterized by the sudden appearance of very sophisticated fineline ceramics and the introduction of Wari-influenced wares from coastal and highland groups with Wari connections. The iconography on finelines at San José de Moro embodies the old and the new synthesized together to create a comprehensive new Moche ideology and polity. As Bawden (2001) found at Galindo, the emerging ideologies of many Late Moche sites included elements of an old Moche tradition revised with new ideological and mythological elements that helped legitimize and explain the changes that occurred due to fluctuating environmental and sociopolitical condi-

8 Aludimos aquí al sugestivo título del artículo de Pineda Camacho (2003) «El poder de los hombres que vuelan», en el que trata acerca de los estudios de Reichel Dolmatoff sobre chamanismo.

9 Fuertemente relacionadas con actividades ceremoniales durante los Horizontes Medio (coincidiendo éste con la expansión Huari) y Tardío. Véase Ángeles Falcón 2008 y Tantaleán 2008.

10 Hasta entonces, en forma específica (taxon 421.111.12), sólo contábamos con los datos proporcionados por Samuel Martí (1955/1966) sobre el llamado «constructor de flautas» de Paracas, Ica (véase Hickmann 1990: 356). Por su parte, el importante hallazgo de las flautas óseas de Caral, si bien aporta a nuestro estudio datos sobre la ritualidad de estos aerófonos, no nos permite establecer ni evaluar relaciones directas, puesto que son flautas de diferente taxonomía.

11 sanjosedemoro.pucp.edu.pe/descargas/articulos/identidadesfemeninas.pdf. 
tions (...). The Wari culture was probably perceived as successful and powerful, and elites at San José de Moro would have desired artifacts that manifested that power. These visual markers of contact with powerful individuals would have instilled awe in the local commoners and reinforced the power that elites had over others»

Por su parte, los estudios de Castillo Butters y Rengifo Chunga a partir de las excavaciones en San José de Moro, avanzan en el conocimiento de identidades y funciones sociales en el complejo cultural Moche, principalmente del Periodo Transicional, coincidente y en contacto con los complejos Huari, Pachacámac y Cajamarca. Particularmente tratan acerca de la función social de la mujer en el poder ideológico, analizando los contextos funerarios de las llamadas «sacerdotisas» o «chamanas». Cráneos humanos, morteros líticos, copas, tocados, máscaras de metal e importante cerámica, constituyen parte de los elementos emblemáticos de su poder. Entre esos contextos, se encuentra el de una mujer constructora de flautas, con los objetos propios de su oficio (Figura 3 izquierda), oficio que, sin duda, respondió a las demandas rituales de las importantes señoras sepultadas en su proximidad (Figura 3 abajo a la derecha). Hablaríamos en este caso de una «especialista incorporada» a las funciones rituales de elite (Brumfiel y Earle 1987; Costin 1991), esto es de una especialista (o un oficio especializado) incorporada a la parafernalia emblemática de los personajes de elevado rango. El dato técnico más significativo y preciso que este contexto nos ofrece es la presencia de una flauta, cuya afinación respondería a los puntos del sistema «pichqa-tawa», observando con exactitud la perforación de los orificios con las unidades de medida y complementariedad del sistema (Gudemos 2011b). Por cierto, necesitamos realizar más estudios, pero por los análisis de las simulaciones de laboratorio que hicimos a partir de los datos publicados, podríamos estar hablando de un prototipo de afinación conforme a los datos determinados en nuestra investigación.

¿Sería esta constructora una especialista en la tradición musical huari «incorporada» al culto local en la nueva dinámica de relaciones que Johnson observa? ¿Serían estas flautas codificadoras de sistemas específicos, importantes en el concepto mágico de su sonido? ¿Serían estas flautas imprescindibles en las prácticas rituales de las señoras chamanas, influidas por nuevos conceptos incorporados en dichas actividades? Las observaciones de Castillo Butters y Rengifo Chunga (2008: 6), son elocuentes al respecto:

«Las tumbas de San José de Moro (...) ofrecen la posibilidad de abordar el tema de la identidad y los roles productivos a partir de contextos funerarios donde estos especialistas aparecen asociados a sus herramientas de trabajo. En base a esta evidencia podemos argumentar que hubo un tratamiento preferencial, y un patrón funerario recurrente, concedido a especialistas ligados con la producción de objetos de alta calidad que permitían la distinción social y que eran esenciales en la materializaron del sistema ritual».

Este hallazgo nos abre así nuevas perspectivas de estudio al tiempo que ofrece evidencias contundentes. 

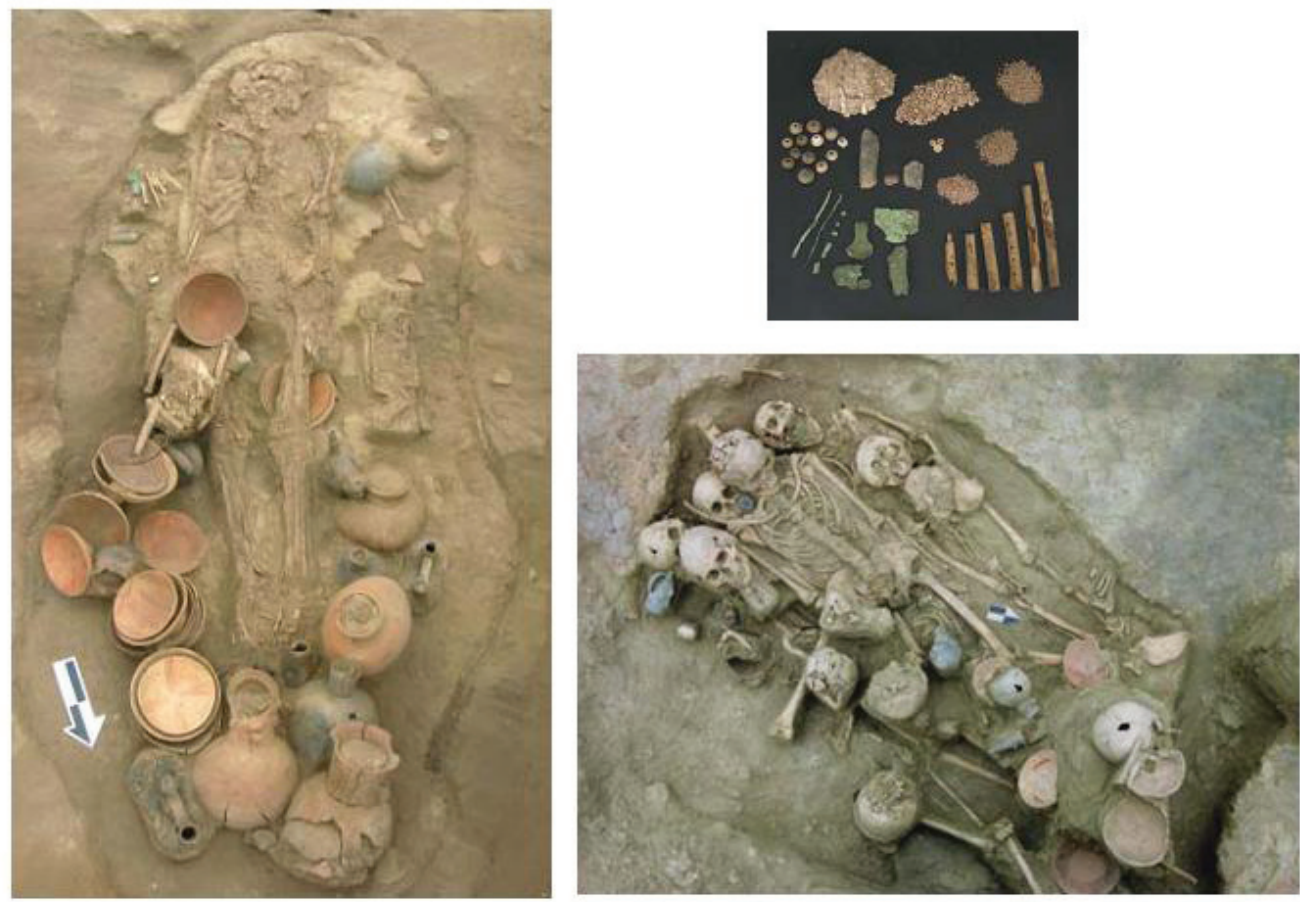

Figura 3: Izquierda: «Posible talladora de quenas de hueso», contexto funerario M-U1403. Derecha, arriba: Algunos elementos del contexto funerario M-U1403 (véase detalle de una flauta ósea completa y otras en proceso de construcción) Abajo: Mujer-chamán, contexto funerario M-U1221 (Castillo Butters y Rengifo Chunga 2008: 11-12). Programa Arqueológico San José de Moro. Perú. Imágenes reproducidas con autorización de su Director Científico, Dr. Castillo Butters.

\section{Los sonidos del vuelo del yajé}

El ritual andino en su vinculación con las culturas amazónicas a través del uso de plantas psicotrópicas, ha sido ampliamente tratado. Los estudios etnográficos de Reichel Dolmatoff entre los kogui y los tukano del Vaupés son elocuentes en lo que atañe a la relación entre sonido (cantos, música), consumo de plantas alucinógenas y los «vuelos rituales del yajé». Aunque sus observaciones permanecieron siempre asidas a una interpretación simbólica de base freudiana (Pineda Camacho 2003: 30), resulta para nosotros interesante la lectura cultural que Reichel Dolmatoff hace del chamanismo «como un sistema coherente de creencias y prácticas religiosas que tratan de organizar y explicar las interrelaciones entre el cosmos, la naturaleza y el hombre» (Reichel Dolmatoff 1988: 23) y cómo, a partir de su experiencia etnográfica, aplica esa lectura al estudio del concepto de chamanismo en el arte de la orfebrería prehispánica. Pineda Camacho (2003: 20, citando a Reichel Dolmatoff 1988) opina que en la orfebrería se manifiesta más claramente que en otras manifestaciones artísticas el complejo chamánico de los indígenas americanos, «donde el ícono del vuelo extático es su principal símbolo, 'pues el vuelo siempre será la imagen del hombre trascendente'». 
Para Reichel Dolmatoff (1988: 26) el empleo de plantas psicotrópicas «está estrictamente relacionado con el llamado vuelo chamánico, es decir, con la sensación de una disociación durante la cual el espíritu del chamán se separa de su cuerpo y penetra en otras dimensiones del cosmos, sea para encontrar en ellas la curación de las enfermedades, sea para consultar con los seres sobrenaturales o ancestrales». Ese vuelo extático, para Reichel Dolmatoff, «constituye el paradigma de la idea de transformación inherente al chamanismo; el chamán se transforma, bajo la influencia de los alucinógenos, en jaguar, águila, etc.: se comunica con otras esferas del cosmos, con otros seres sobrenaturales y observa y vigila a sus enemigos».

Según los estudios de los síndromes neurológicos asociados al consumo de hongos y plantas alucinógenos en la Amazonía peruana, el consumo de ayahuasca provoca alucinaciones que culturalmente se interpretan como «migraciones, en donde los guías espirituales intentan conducirlos a otras dimensiones espirituales de la vida» (Carod Artal 2005: 54). Migraciones que se asumen como «vuelos». El consumo de ayahuasca liana amarga, yajé y hoasca, estuvo y aún está muy difundido, principalmente, en varias regiones de la Amazonía en Bolivia, Perú, Brasil, Venezuela y Colombia. Como este autor describe, se trata de infusiones de plantas con propiedades psicoactivas, como la Banisteriopsis caapi y Psychotria viridis, siendo la triptamina (N-dimetil-triptamina [DMT]) el principal componente alucinógeno. Los efectos (interpretados conforme al contexto cultural de quien los sienta) producen imágenes visuales intensas, brillantes y de fugaz desplazamiento, y alucinaciones auditivas en tonos graves (relacionadas con la audición interna del torrente sanguíneo) y muy agudos (relacionadas con el sistema nervioso). No en vano, durante las prácticas rituales el consumo de alucinógenos y el «vuelo extático» se acompañan con toques de trompetas o tambores (sonidos graves) y flautas globulares del tipo silbato o longitudinales óseas como las que estudiamos, por ejemplo (sonidos agudos). Es así que en los contextos funerarios de las chamanas de San José de Moro los instrumentos musicales se observan como parte integrante de su parafernalia.

El consumo en la Amazonía y en diferentes regiones andinas de preparados alucinógenos extraídos de la Anadenanthera peregrina y la Virola calophylla (cuyas cortezas son ricas en alcaloides derivados de la triptamina, como la bufotenina), produce también alucinaciones visuales y, en menor medida, auditivas (Carod Artal 2005: 54). En los Andes Meridionales, en tiempos prehispánicos, el consumo de Anadenanthera colubrina, potente igualmente en alcaloides como la bufotenina, y la Nicotiana tabacum fue el más difundido (Torres 1986, 1996).

Es interesante observar la importancia que las plantas psicotrópicas tuvieron en la economía de intercambio y relaciones de interacción en el altiplano sur andino, como observan Angelo Zelada y Capriles Flores (2000). En términos globales, sin duda fue intensa la interculturalidad entre las sociedades andinas altiplánicas y costeras y las sociedades orientales de la Amazonía y el Gran Chaco. Interculturalidad sustentada, por cierto y en gran parte, por ritos afines que promovían un importante tráfico de plantas psicotrópicas. Una dinámica cultural en la que es interesante observar una gran variedad estilística de una misma concepción iconográfica. 


\section{El vuelo extático}

En esa misma dinámica apareció una particular iconografía significativamente importante para nuestro estudio. De acuerdo con Dale Olsen (2005: 51-53), hablamos de la iconografía del «vuelo extático». Ésta responde a un estereotipo representativo básico: personaje con importante tocado en postura decúbito ventral (en la mayoría de los casos con plataforma de apoyo), cabeza forzadamente inclinada hacia atrás, miembros inferiores flexionados hacia atrás/arriba y manos sosteniendo elementos tales como vasos, trompetas, flautas o pipas de fumar. Elementos «activos», esto es en función sonora o en función de ingesta. Generalmente este personaje principal está acompañado por «asistentes» con funciones específicas: tamborileros, portadores de vaso o «acompañantes de vuelo». La representación de un flautista en una vasija Recuay de la colección John y Mary Carter de la Universidad Estatal de Florida es elocuente al respecto (Figura 4b). El flautista tañe un aerófonono de igual taxon a los que estudiamos. La muesca de embocadura y la equidistancia de los orificios de digitación son propias de la tipología «Chancay» en nuestro estudio. Cinco «asistentes» en actitud hierática portando vasos (posiblemente con bebidas fermentadas o infusiones psicoactivas) completan la escena ritual.

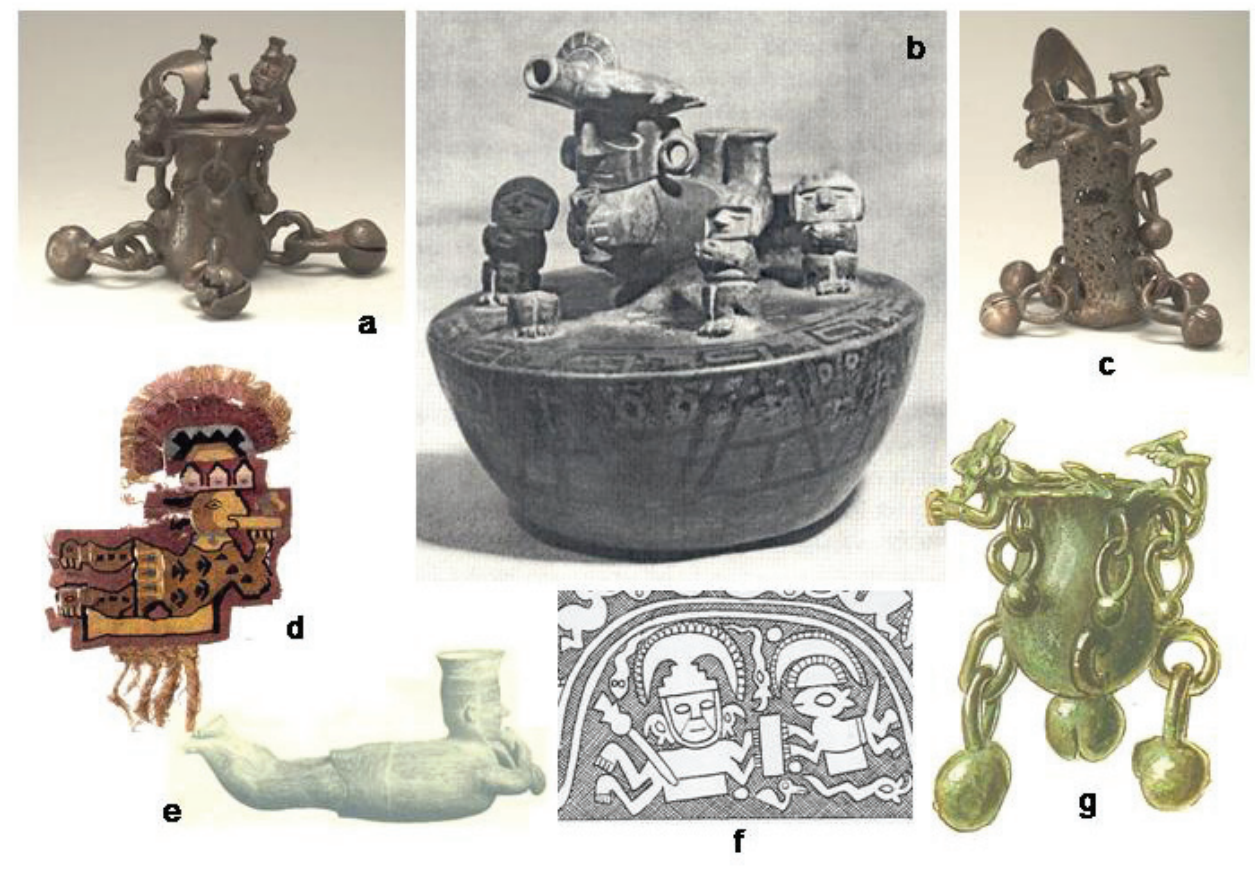

Figura 4: El vuelo extático. a: Remate de bastón de bronce Chimú [MA7495]. b: Vasija de cerámica Chancay (Olsen 2005). c: Remate de bastón de bronce Chimú [MA7493]. d: Fragmento de tejido Ancón (Reiss y Stübel 1880-1887). e: Vasija escultórica de cerámica Chincha (R. y M. d'Harcourt 1925). f: Detalle de decoración repujada de un cuenco metálico Chimú, Trujillo, (Baessler 1902). g: Remate de bastón de bronce Chimú, Virú (Baessler 1902). 
Identificamos la iconografía del «vuelo extático» en piezas metálicas chimú, tejidos ancón, vasijas escultóricas e iconografía decorativa huari y vasijas escultóricas chincha (Figuras 4 y 5). En el caso específico de la pieza chincha (Figura 4e) observamos la clara representación de una flauta tipo «Chancay Grande» (véase Gudemos 2001b). Pensamos que esta iconografía alude, de alguna manera, a prácticas rituales que habrían demandado modos musicales determinados y sonidos, cuya tímbrica habría sido ritualmente equiparada a la de los sonidos percibidos en «vuelo extático» bajo los efectos de sustancias psicoactivas.

Es interesante constatar que tanto las flautas óseas que estudiamos como esta particular iconografía, comparten una misma dispersión geográfica y temporal, cuyo inicio asociamos con la expansión Huari a partir del Horizonte Medio (con la impronta cultural sudcosteña Nazca/Paracas y altiplánica Tiahuanaco, como tratamos en anteriores trabajos) (Gudemos 2009a), y que ambas se habrían asimilado culturalmente con mayor fuerza en la Costa Central y áreas de influencia que, como sabemos, fue donde los grupos de elite concentraron entonces la principal actividad ceremonial ${ }^{12}$.

\section{Alucinógenos, «vuelo extático» y simbología iconográfica}

La relación de estas flautas con un contexto ritual emerge en nuestros estudios como evidente. La vinculación entre la posición de «vuelo» con la producción de sonido y el consumo de alucinógenos (fumados, inhalados o bebidos) es elocuente. La particular posición decúbito ventral con la fuerte torsión de cabeza hacia atrás nos remitió a la tesis de Wasen de 1965 sobre inhalación de alucinógenos en América del Sur, a los estudios de Berenguer de la década de 1980 sobre parafernalia de inhalación de alucinógenos e iconografía prehispánica en los Andes Centro-Meridionales y, a través de ellos, a las Memorias Cientificas de Rivero de 1857.

Del estudio sobre la inhalación de alucinógenos en Tiahuanaco de José Berenguer (1989) nos interesa particularmente la búsqueda de relaciones que, a partir de las posturas que los indígenas adoptan para inhalar alucinógenos, establece el autor a nivel iconográfico. Berenguer llama la atención, como oportunamente lo hizo Henry Wasen en 1965 a partir de observaciones hechas por Max Uhle (1915: 136), sobre una imagen publicada por Mariano Eduardo de Rivero en 1857 en el primer volumen de su Colección de Memorias Científicas (Figura 5). En la imagen el autor ilustra un momento en la vida de los yaruro de Puerto San Simón, en el que uno se encuentra inhalando yopo, asistido por otro. Éste muestra una postura genuflexa habitual entre los indígenas sudamericanos durante la inhalación de sustancias ricas en alcaloides. En algunos casos dicha postura se habría «facilitado» recostando al individuo en decúbito ventral sobre pequeñas plataformas, como las que identificamos en las representaciones del «vuelo extático» que estudiamos. A partir de esto pensamos en una comprensión iconográfica simbólica de carácter ritual, en la que se alude a determinadas prácticas que incluyeron el consumo de alucinógenos, posiblemente por inha-

12 La compilación de Pinedo y Tantaleán Arqueología de la Costa Centro Sur Peruana (2008) y la edición de Eeckhout «Arqueología de la Costa Central del Perú en los Periodos Tardíos» (2004) ofrecen importante información al respecto. 
lación (de polvo de semillas de variedades de Anadenanthera, por ejemplo) o ingesta de infusiones (de Banisteriopsis caapi, entre otras), como se ha constatado entre las culturas andinas. Dicha comprensión iconográfica habría esquematizado la postura decúbito ventral y la torsión hacia atrás de la cabeza, resolviéndose conceptualmente en una imagen hierática «en vuelo extático».

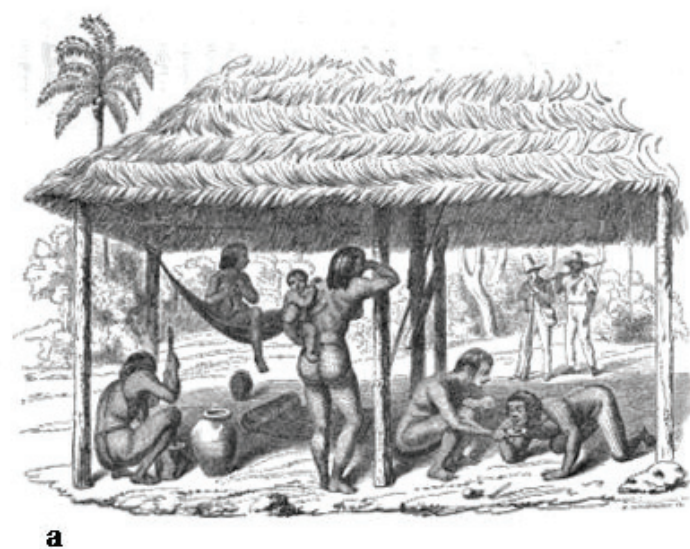

a b

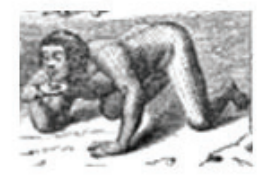

C

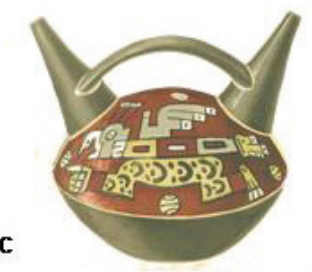

d

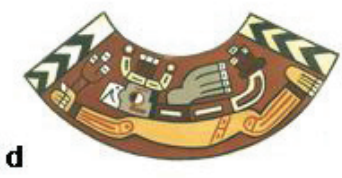

Figura 5: El vuelo del yajé: Una posición iconográficamente ritualizada. a: Colección de Memorias Científicas, primer volumen (Rivero 1857). b: Rivero 1857, detalle. c: Vasija Huari/Pachacámac

(Baessler 1902). d: Fragmento de decoración de una vasija Huari/Pachacámac (Baessler 1902). e: Cuenco Huari/Atarco [MN 117, MVM].

Berenguer considera no sólo la torsión de la cabeza hacia atrás durante el consumo de alucinógenos, sino particularmente durante las convulsiones posteriores a la ingesta o inhalación, en las que «voltean el vientre hacia arriba (...) y la espalda la voltean a donde está el estómago», como registra Reichel Dolmatoff (1978: 124 ss.) en sus trabajos sobre los desana:

«Ante nuevas preguntas, nuestros informantes enseñaban la posición alzando los puños cerrados a la altura de los ojos y al mismo tiempo doblaban el cuerpo hacia atrás en una postura intensamente forzada. Es decir, representaban la posición del hombrejaguar con la misma postura convulsiva que adopta una persona bajo la influencia del rapé (...). Si las convulsiones de un hombre intoxicado significan que está listo para volverse jaguar, la imagen de un jaguar 'al revés' se basaba también, según toda probabilidad, en un hecho observado» (Reichel Dolmatoff 1978: 124)

Este registro de Reichel podría igualmente referirse a los «danzantes jaguar» de las pinturas rupestres de la cultura La Aguada en los Andes Meridionales, en frenesí convulsivo bajo los efectos de la Anadenanthera colubrina, variedad cebil (Gudemos 
2001a, 2003), como a los «chamanes extáticos» de los textiles Paracas, cuyo trance, según Paul y Turpin (1986: 21), pudo ser inducido por danzas, sonidos monótonos producidos por la música, privación sensorial o fuertes intoxicantes. Seres ingrávidos que parecen iniciar vuelo en pleno efecto convulsivo.

\section{Consideraciones finales}

Por todo lo expuesto concluimos que estamos ante un caso en el que prácticas rituales específicas habrían demandado sonidos igualmente específicos. Una demanda que promovió el desarrollo de una mano de obra altamente especializada, tanto que llegó a determinar estructuras acústicas a partir de un sistema de medición por longitudes complementarias. Estaríamos, pues, frente a un complejo sistema ceremonial, de amplia dispersión geográfica y temporal, que involucró una trama de especialidades artísticas y funciones sociales que hoy rescatamos técnica e iconográficamente.

Agradecimientos: Agradezco a Luis Jaime Castillo Butters, Director Científico del Programa San José de Moro (Pontificia Universidad Católica del Perú) por su atenta colaboración y por permitirme utilizar imágenes del Programa. Asimismo, agradezco a Ana Verde Casanova y a Nuria Moreau del Museo de América de Madrid por su gentileza en enviarme las imágenes de las piezas metálicas Chimú solicitadas para este trabajo.

\section{Referencias bibliográficas}

Ángeles FALCón, Rommel

2008 «Del Intermedio Temprano al Horizonte Medio: una visión de la Costa Centro Sur desde el Valle de Asia», en Arqueología de la Costa Centro Sur Peruana. Omar Pinedo y Henry Tantaleán, comps., pp. 103-146. Lima: Avqi Ediciones.

Angelo Zelada, Dante y José Mariano Capriles Flores

2000 «La importancia de las plantas psicotrópicas para la economía de intercambio y relaciones de interacción en el Altiplano Sur andino». Complutum 11: 275-284.

BAESSLER, Arthur

1902-1903 Ancient Peruvian Art. Contribution to the Archaeology of the Incas. Leipzig: Karl W. Hiersemann.

BEREnguer, José

1987 «Consumo nasal de alucinógenos en Tiwanaku: una aproximación iconográfica». Boletín del Museo Chileno de Arte Precolombino 2: 33-53.

BrumfIEL, Elizabeth y Timothy EARLE

1987 «Specialization, Exchange, and Complex Societies: An Introduction», en Specialization, Exchange, and Complex Societies, E. Brumfiel y T. Earle, eds., pp. 1-9. Cambridge: Cambridge University Press. 
CARod Artal, Francisco Javier

2005 «Síndromes neurológicos asociados con el consumo de hongos y plantas alucinógenos». Elementos: Ciencia y Cultura 12 (60): 49-57. Puebla.

Castillo Butters, Luis Jaime y Carlos E. Rengifo Chunga

2008 «Identidades funerarias femeninas y poder ideológico en las sociedades Mochicas», en Señores de los reinos de la luna, K. Makowski, ed. Lima: Banco de Crédito del Perú. Documento electrónico, $<\mathrm{http}$ ://sanjosedemoro.pucp.edu.pe/descargas/articulos/identidadesfemeninas.pdf>, con acceso el 20/12/2011.

Costin, Cathy Lynne

1991 «Craft specialization: Issues in defining documenting, and explaining the organization of production». Archaeological Method and Theory 3: 1-56.

Eeckhout, Peter (editor)

2004 «Arqueología de la Costa Central del Perú en los Periodos Tardíos». Bulletin de l'Institut Français d'Études Andines 33 (3).

Gudemos, Mónica

1998 «Flautas óseas precolombinas de la Costa Central de Perú, ¿organizaciones formales y sonoras preestablecidas?». Baessler-Archiv 46: 107-134. Berlín.

2001a La Música Como Emblema de Poder en los Andes Centro-Meridionales. Estudios en Arqueomusicología para América Andina. Tesis Doctoral. Universidad Complutense de Madrid.

2001b «Módulos de afinación prehispanos». Baessler-Archiv 48: 43-105. Berlín.

2003 «Una danza de integración regional en las pinturas rupestres de La Salamanca?». Revista Española de Antropología Americana 33: 83-119.

2005 «Capac, Camac, Yacana. El Capac Raymi y la música como emblema de poder». Anales del Museo de América 13: 9-52.

2006 «Principio de correlación en la determinación acústica de los módulos de afinación de las flautas arqueológicas huari». Resúmenes. XVII Conferencia de la Asociación Argentina de Musicología - XIII Jornadas Argentinas de Musicología. La Plata. Buenos Aires.

2008 «Taqui Qosqo Sayhua. Espacio, sonido y ritmo astronómico en la concepción simbólica del Cusco incaico». Revista Española de Antropología Americana 38 (1): 115-138.

2009a «Principio de correlación en la determinación acústica de módulos de afinación andinos prehispánicos». Revista Española de Antropología Americana 39 (1): 169-184.

2009b «Pichqa-Tawa. Sistema de medición por longitudes proporcionales complementarias». Ponencia y resúmenes del XVI Congreso Peruano del Hombre y la Cultura Andina y Amazónica. Universidad Nacional Mayor de San Marcos. Lima, Octubre de 2009.

2009c «La tensa coexistencia de los espacios-tiempos ceremoniales integrados. El hábito de San Francisco y la camiseta de cumbi». Revista Española de Antropología Americana 40 (1): 169-195.

2011a «Pichqa-Tawa. Sistema de medición andino prehispánico». Anales del Museo de América 17. [En prensa].

$2011 b$ «The Pre-Hispanic Measuring System of Complementary Lengths pichqa-tawa and the Determination of the Huari Ceremonial Sound (Peru, 600-1100 CE)». Ponencia. XII Congress of the ICTM Study Group for Music Archaeology: Sound \& Ritual in Music Archaeology Bridging Material \& Living Cultures. Valladolid, Septiembre de 2011. 
Gudemos, Mónica y Julio Catalano

2009 «El cuerpo del sonido. Flautas antropomorfas de tradición Bahía». Revista Española de Antropología Americana 39 (1): 195-218.

D'Harcourt, R. y M.

1925 La Musique des Incas et ses survivances (Planches). París: Librairie Orientaliste Paul Geuthner. Pl. XXIV.

HiCKMANN, Ellen

1990 Musik aus dem Altertum der Neuen Welt. Archäologische Dokumente des Musizierens in präkolumbischen Kulturen Perus, Ekuadors und Kolumbiens. Frankfurt am Main: Peter Lang.

JoHNSON, Ilana

2008 «Portachuelo de Charcape: Daily Life and Political Power in the hinterland during the Late Moche Period», en Arqueología Mochica, Nuevos Enfoques, L. Castillo, H. Bernier, G. Lockard y J. Rucabado, eds., pp. 261-274. Lima: Pontificia Universidad Católica del Perú. Instituto Francés de Estudios Andinos.

Olsen, Dale A.

2005 Music of El Dorado. The Ethnomusicology of Ancient South American Cultures. Gainesville: University Press of Florida.

PAul, Anne y Solveig A. Turpin

1986 «The Ecstatic Shaman theme of Paracas textiles». Archaeology 39 (5): 20-27.

Pineda CAmacho, Roberto

2003 «El poder de los hombres que vuelan. Gerardo Reichel Dolmatoff y su contribución a la teoría del chamanismo». Tabula Rasa 1: 15-47. Bogotá.

Reichel Dolmatoff, Gerardo

1978 El chamán y el jaguar. México: Siglo Veintiuno Editores.

1988 Orfebrería y chamanismo. Un estudio iconográfico del Museo del Oro. Medellín: Editorial Colina.

REISs, Wilhelm y Alphons STÜBEL

1880-1887 Das Todtenfeld von Ancón in Perú. Ein Beitrag zur Kenntnis der Kultur und Industrie des Inca-Reiches, 3 vols. Berlín.

Rivero y Ustaritz, Mariano Eduardo de

1857 Colección de Memorias Científicas Agrícola e industriales publicadas en diferentes épocas, Tomo I. Bruselas: Imprenta de H. Goemaere.

TANTALEÁN, Henry

2008 «Al Sur de Pachacamac: una introducción a la arqueología de la Costa Centro Sur peruana», en Arqueología de la Costa Centro Sur Peruana, Omar Pinedo y Henry Tantaleán, comps., pp. 11-38. Lima: Avqi Ediciones.

TORRES, C. M.

1986 «Tabletas para Alucinógenos en Sudamérica: Tipología, Distribución y Rutas de Difusión». Boletín del Museo Chileno de Arte Precolombino 1: 37-53.

1996 «Archaeological Evidence for the Antiquity of Psychoactive Plant Use in the Central Andes». Annali dei Musei Civici-Rovereto 11: 291-326. 
Uhle, F. Max

1915 «Las tabletas y tubos de rapé en Chile». Revista de Historia y Geografía 16 (20): 114-136. Santiago de Chile.

WASSEN, S. H.

1965 «The use of some specific kinds of South American Indians snuff and related paraphernalia». Etnologiska Studier 1: 1-116. Göteborg. 